\title{
Treatment of Orbital Complications Following Acute Rhinosinusitis in Children
}

\author{
Yuzhu Wan ${ }^{1,2}$, Guanggang Shi ${ }^{1,2}$, Haibo Wang ${ }^{1,2}$ \\ ${ }^{1}$ Department of Otorhinolaryngology, Shandong Provincial Hospital Affiliated to Shandong University, Jinan, China \\ ${ }^{2}$ Institute of Eye and ENT, Shandong Provincial Hospital Affiliated to Shandong University, Jinan, China
}

Background: The orbital complications account for about $80 \%$ of all complications secondary to acute rhinosinusitis. If the treatment is not correct and in time, orbital complications could progress rapidly, leading to optic neuritis, cavernous sinus thrombophlebitis or life-threatening intracranial complications.

Aims: To evaluate the therapeutic efficacy of conservative therapy for the patients with orbital cellulitis and endoscopic sinus surgery (ESS) performed on patients with subperiosteal abscess (SPA) secondary to acute rhinosinusitis in children.

Study Design: Retrospective cross-sectional study.

Methods: The retrospective study included 31 pediatric patients with orbital complications secondary to acute rhinosinusitis. In all cases, intensive treatment was initiated with a combination of oral or intravenous antibiotics, glucocorticoid and gelomyrtol forte after admission. ESS was performed if an improvement in the condition of patients did not occur after 48 hours. However, the patients with orbital SPA, motility disorders of eyeball or decreased vision received ESS immediately within 24 hours.

Results: Sixteen patients were cured by conservative therapy and 15 patients by ESS. All of the signs and symptoms disappeared after conservative therapy or ESS. There were no recurrences within the follow-up period of 1 to 8 years. Conclusion: Conservative therapy is an effective method for patients with inflammatory edema and most cases of orbital cellulitis in children. SPA can be cured by ESS.

Keywords: Acute rhinosinusitis, orbital cellulitis, subperiosteal abscess, surgical drainage, orbital complication
In children, acute rhinosinusitis represents acute infection of the nose and paranasal sinuses. It is commonly associated with upper respiratory tract infections due to viruses such as adenovirus, influenza virus, rhinovirus and parainfluenza virus. Progression of acute sinusitis may result in serious complications such as soft tissue infection, inflammation of the bone, orbital complications, intracranial complications, and so on (1). The orbital complications, as a result of the spread of infection from the sinuses to adjacent tissues, are the most frequent complications, which accounts for about $80 \%$ of all complications. If the treatment is not correct and in time, orbital complications could progress rapidly, leading to optic neuritis, cavernous sinus thrombophlebitis or life-threatening intracranial complications $(2,3)$. In order to explore the correct treatment of orbital complications secondary to acute rhinosi- nusitis, a retrospective analysis of 31 pediatric patients with orbital complications was made in our hospital. The effect and prognosis of conservative therapy and ESS were displayed in this article.

\section{MATERIALS AND METHODS}

A retrospective medical chart review was performed on patients aged 12 years-old or younger who were treated for orbital complications secondary to acute rhinosinusitis in our hospital between March 2006 and March 2013. The study was approved by the local Ethical Committee on Human Experimentation of the Hospital. All patients sought medical help initially for orbital infections in the ophthalmology, pediatrics 
or ENT departments. Orbital or sinus computed tomography (CT) or magnetic resonance imaging (MRI) scans were performed to confirm the diagnosis of orbital complications and concomitant sinusitis. Cases of orbital cellulitis without concomitant sinusitis were excluded. There was an immediate consultation with the ophthalmologist when there was a suspicion of orbital complications or the clinical diagnosis was an orbital complication. Additional informed consent was obtained from all individual participants for whom identifying information is included in this article.

Table 1 summarizes relevant clinical and operative details of the 31 patients ( 23 males and 8 females). The age of patients ranged from 11 months to 12 years (mean age 8.7 years). In total, 17 and 8 patients made their first visit to the ophthalmologic and pediatric department, respectively, before a final diagnosis was made. The most common orbital complications diagnosed were orbital cellulitis (14 cases), subperiosteal abscess ( 13 cases), and inflammatory edema ( 4 cases). No patient with orbital abscess or cavernous sinus thrombosis was observed in this series. The most common presenting symptoms were eyelid edema, proptosis (Figure 1,2) and fever. Three patients (cases 6, 8 and 9) had reduced visual acuity, and one had diminished eye movements. CT scanning of the orbits or sinuses was performed after operation in some patients.

The diagnoses were determined based on anamnesis, signs and symptoms, CT or MRI scans with coronal and axial projections.

In all cases, intensive treatment was initiated with intravenous antibiotics (flucloxacillin), glucocorticoid (methylprednisolone) and oral gelomyrtol forte after admission (4). ESS was performed when an improvement in the patient's condition did not occur after 48 hours. But patients with orbital SPA, motility disorders of the eyeball or decreased vision received ESS immediately within the first 24 hours. ESS included opening of sinus and intranasal drainage of the SPA. After undergoing general anesthesia, a complete opening of the sinuses associated with orbital complication was performed and part of the lamina papyracea near the abscess was removed (Figure 3). Then, the abscess could be found in the superiomedial, medial or below orbit, and purulent secretion was cleared off. The cavity of orbital SPA was rinsed repeatedly. Then, the nasal cavity was filled with NasoPore (Polyganics; Netherlands) and cleared off on day 3 after surgery.

Oral antibiotics (roxithromycin) and gelomyrtol forte were used for one to four weeks and mometasone furoate aqueous nasal spray was used for one to three months on patients (above 3 years-old) with allergic rhinitis.

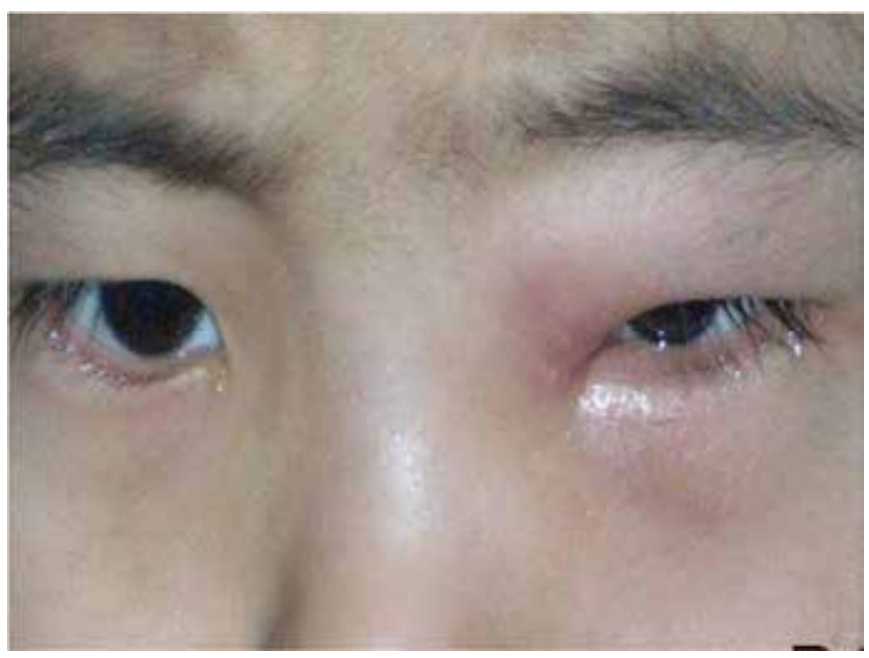

FIG. 1. Indicating left eyelid edema and proptosis (Case 5)

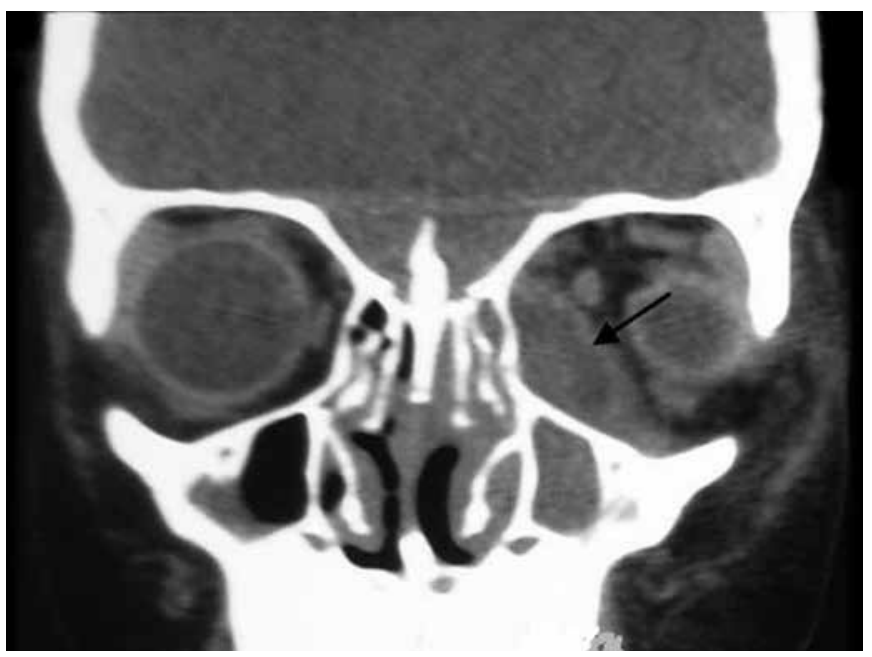

FIG. 2. Arrow indicating SPA located in the left orbit (Case 5)

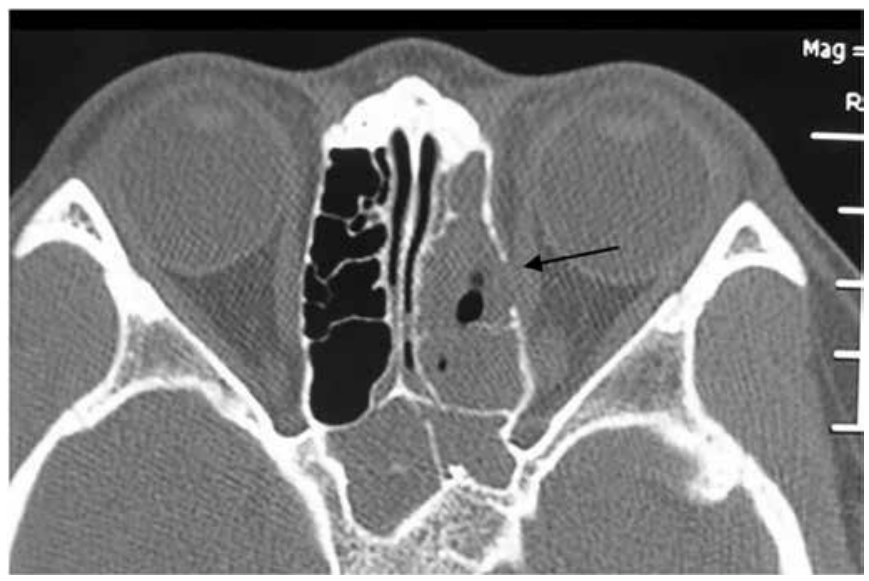

FIG. 3. Arrow indicating the small defect in the lamina papyracea removed by ESS (Case 1) 


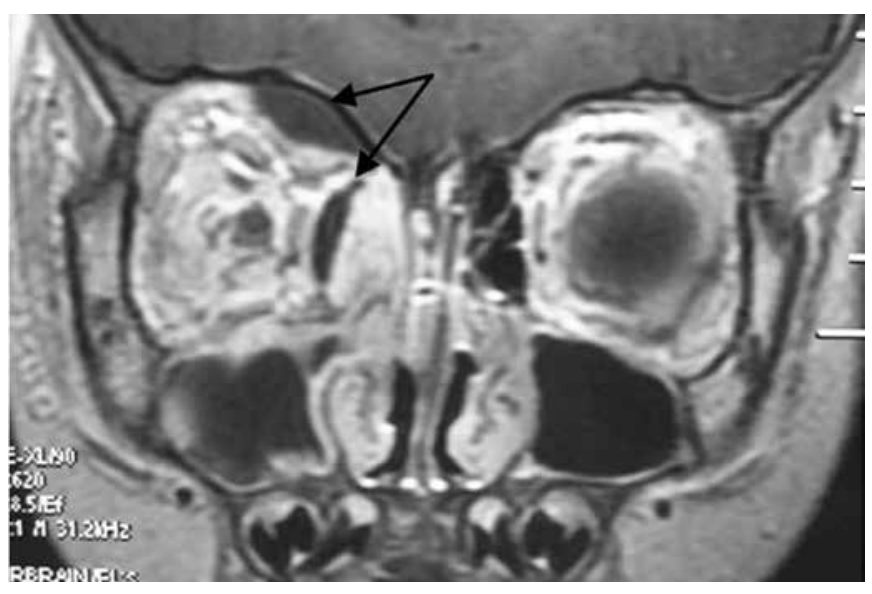

FIG. 4. MRI scan of two SPAs (Case 2), Arrow indicating two SPAs located in the medial and superior orbit

\section{RESULTS}

In total, 16 patients were cured by conservative therapy and 15 patients by ESS in our department. The eyelid edema of 4 patients (cases 10,11, 12 and 16) with inflammatory edema disappeared after 3 days of conservative therapy. The symptoms of 12 patients with orbital cellulitis, such as eyelid edema, proptosis and fever were improved after 7 days of intravenous antibiotics, glucocorticoid and oral gelomyrtol forte. The patients were discharged from hospital on appropriate oral antibiotics for 4 weeks. The decreased vision of two patients (cases 6 and 8 ) with orbital cellulitis returned to normal on day 7 after sphenoidotomy and intranasal antrostomy was performed immediately after admission. The symptoms of 13 patients with SPA, such as proptosis, headache, fever, diminished movement disappeared on 4 to 8 days after the opening of ethmoidal cellules and abscess drainage. The sinusitis and SPAs of one patient (case 2) who had two SPAs (Figure 4) located in the superiomedial orbit were cured at the same time. All signs and symptoms of the patients disappeared after conservative therapy or ESS. The CT scans revealed that the SPA disappeared and sinusitis was improved after surgery. There were no recurrences within the follow-up period of 1 to 8 years.

\section{DISCUSSION}

Acute orbital complication is a severe disease, which may cause mortality if it is not treated correctly and in a timely manner. Orbital complications seem to be more frequent in children than in adults and are directly related to the intimate anatomical relations between the paranasal sinuses and orbital contents (5). The orbit is intimately associated with the sinus- es, especially the maxillary, ethmoid and frontal sinuses. Also, the optic canal is closely adjacent to the posterior ethmoid and sphenoid sinuses; the lamina papyracea of children is a very thin layer of bone plate which is between the eye and ethmoid sinuses. There are many small bone dehiscences on it. The lamina papyracea are rich in a venous system which lacks valves and constitutes a vascular network, so that the blood can move freely between ethmoid sinuses and orbit content $(4,6)$. The nasal cavity of children is narrower and the nasal mucosa is tenderer than that of adults; thus, the sinuses are easily blocked by edematous mucosa during an acute infection, and the infection can spread from sinuses to the orbit (7).

The mode of infection spread from the sinuses to the orbits is usually by bacterial thrombophlebitis through valveless veins, direct extension from bony erosion, or via congenital or acquired bony dehiscences (8).

The original classification of Chandler et al. (9), which was published in 1970 and had been one of the most employed classifications, divided orbital infections into five categories: inflammatory edema, orbital cellulitis, subperiosteal abscess, orbital abscess and cavernous sinus thrombosis.

In recent years, the incidence of orbital complications had been greatly reduced because of the early application of broadspectrum antibiotics (10).

At present, there is still a lot of debate about the effect of conservative therapy or surgical intervention of orbital complications secondary to acute rhinosinusitis in children. Most scholars have suggested that inflammatory edema could be cured only by conservative therapy. Orbital SPA, orbital cellulitis and orbital abscess should be treated by surgery, which should be performed in time to avoid causing more serious irreversible complications. Cavernous sinus thrombosis is a serious condition requiring enhanced medical treatment (11).

Conservative treatment, which included oral or intravenous antibiotics in combination with topical decongestants or mucus thinning agents, was the first option for the inflammatory edema and orbital cellulitis in our study (7). However, ESS should be performed immediately for patients with orbital cellulitis concomitant optic neuritis, decreased vision or motility disorders of the eyeball (12).

Inflammatory edema is an inflammation before the orbital septum and generally tends to being isolated from the orbital contents. Sometimes an abscess can form in this region, but such inflammation is not a threat to patients and usually responds to medical treatment (9). In our series, all 4 patients with inflammatory edema recovered after conservative therapy.

Orbital cellulitis is inflammation of the orbital contents and without abscess formation. The symptoms of 12 patients with orbital cellulitis were improved after 7 days of intra- 
TABLE 1. Clinical and surgical details of the 31 cases in this series

\begin{tabular}{|c|c|c|c|c|c|c|c|}
\hline No. & Age & Sex & Complication & Sinus & Signs and symptoms & Treatment & Department \\
\hline 1 & 3 & M & subperiosteal abscess & ethmoid & $\begin{array}{l}\text { proptosis, ptosis, eyelid edema, } \\
\text { headache, fever }\end{array}$ & $\begin{array}{l}\text { ethmoidectomy, } \\
\text { abscess drainage }\end{array}$ & ophthalmology \\
\hline 2 & $61 / 2$ & M & subperiosteal abscess & $\begin{array}{l}\text { ethmoid, sphenoid, } \\
\text { maxillary }\end{array}$ & $\begin{array}{l}\text { proptosis, } \\
\text { chemosis, fever }\end{array}$ & $\begin{array}{l}\text { ethmoidectomy, intranasal } \\
\text { antrostomy, abscess drainage }\end{array}$ & pediatrics \\
\hline 3 & 4 & $\mathrm{~F}$ & subperiosteal abscess (L) & ethmoid, maxillary & $\begin{array}{c}\text { eyelid edema, fever, cough, } \\
\text { nasal obstruction }\end{array}$ & $\begin{array}{l}\text { ethmoidectomy, } \\
\text { abscess drainage }\end{array}$ & ENT \\
\hline 4 & $31 / 12$ & $\mathrm{~F}$ & orbital cellulitis & ethmoid, maxillary & eyelid edema, fever & conservative therapy & pediatrics \\
\hline 5 & $53 / 12$ & M & subperiosteal abscess & $\begin{array}{l}\text { ethmoid, maxillary } \\
\text { Sphenoid }\end{array}$ & $\begin{array}{l}\text { eyelid edema, fever, } \\
\text { maxillofacial swelling }\end{array}$ & $\begin{array}{l}\text { ethmoidectomy, } \\
\text { abscess drainage }\end{array}$ & ophthalmology \\
\hline 6 & 10 & M & orbital cellulitis & ethmoid, maxillary & $\begin{array}{c}\text { proptosis, } \\
\text { decreased vision }(0.05)\end{array}$ & sphenoidotomy & ophthalmology \\
\hline 7 & $28 / 12$ & M & subperiosteal abscess & maxillary & $\begin{array}{l}\text { eyelid edema, proptosis, fever, } \\
\text { diminished movement }\end{array}$ & $\begin{array}{l}\text { ethmoidectomy, } \\
\text { abscess drainage }\end{array}$ & ophthalmology \\
\hline 8 & $117 / 12$ & $\mathrm{~F}$ & $\begin{array}{l}\text { orbital cellulitis, } \\
\text { optic neuritis }\end{array}$ & ethmoid, frontal & $\begin{array}{c}\text { proptosis, } \\
\text { headache decreased vision }\end{array}$ & intranasal antrostomy & ophthalmology \\
\hline 9 & 12 & M & subperiosteal abscess & maxillary & $\begin{array}{l}\text { proptosis, eyelid edema, nasal } \\
\text { obstruction, decreased vision }\end{array}$ & $\begin{array}{l}\text { ethmoidectomy, } \\
\text { abscess drainage }\end{array}$ & ENT \\
\hline 10 & $011 / 12$ & M & inflammatory edema & ethmoid, maxillary & eyelid edema, nasal obstruction & conservative therapy & ophthalmology \\
\hline 11 & $119 / 12$ & M & inflammatory edema & ethmoid, maxillary & eyelid edema, nasal obstruction & conservative therapy & ophthalmology \\
\hline 12 & 11 & M & inflammatory edema & $\begin{array}{l}\text { ethmoid, frontal } \\
\text { maxillary }\end{array}$ & $\begin{array}{c}\text { eyelid edema, } \\
\text { nausea, headache }\end{array}$ & conservative therapy & ENT \\
\hline 13 & $45 / 12$ & M & orbital cellulitis & $\begin{array}{l}\text { ethmoid, sphenoid, } \\
\text { maxillary }\end{array}$ & proptosis, fever, eyelid edema & conservative therapy & ophthalmology \\
\hline 14 & 10 & M & orbital cellulitis & ethmoid, maxillary & $\begin{array}{l}\text { eyelid edema, fever, } \\
\text { nasal obstruction }\end{array}$ & conservative therapy & ophthalmology \\
\hline 15 & $102 / 12$ & M & subperiosteal abscess & ethmoid, maxillary & $\begin{array}{l}\text { proptosis, headache, } \\
\text { eyelid edema, fever }\end{array}$ & $\begin{array}{c}\text { ethmoidectomy, abscess } \\
\text { drainage }\end{array}$ & pediatrics \\
\hline 16 & 10 & M & inflammatory edema & ethmoid maxillary & eyelid edema, headache & conservative therapy & ophthalmology \\
\hline 17 & $58 / 12$ & M & orbital cellulitis & ethmoid, maxillary & proptosis, eyelid edema & conservative therapy & pediatrics \\
\hline 18 & $44 / 12$ & M & orbital cellulitis & ethmoid, maxillary & proptosis, fever, eyelid edema & conservative therapy & pediatrics \\
\hline 19 & 9 & M & subperiosteal abscess & $\begin{array}{l}\text { ethmoid, sphenoid, } \\
\text { maxillary }\end{array}$ & $\begin{array}{l}\text { nausea, proptosis, headache, } \\
\text { eyelid edema }\end{array}$ & $\begin{array}{l}\text { ethmoidectomy, abscess } \\
\text { drainage, intranasal antrostomy }\end{array}$ & ENT \\
\hline 20 & $37 / 12$ & $\mathrm{~F}$ & orbital cellulitis & ethmoid, maxillary & $\begin{array}{l}\text { proptosis, fever, } \\
\text { nasal obstruction }\end{array}$ & conservative therapy & ophthalmology \\
\hline 21 & 12 & M & subperiosteal abscess & $\begin{array}{l}\text { ethmoid, sphenoid, } \\
\text { maxillary }\end{array}$ & proptosis, headache & $\begin{array}{l}\text { sphenoidotomy, } \\
\text { ethmoidectomy, } \\
\text { abscess drainage }\end{array}$ & ENT \\
\hline 22 & 11 & M & orbital cellulitis & ethmoid, sphenoid & $\begin{array}{l}\text { proptosis, headache, } \\
\text { eyelid edema }\end{array}$ & conservative therapy & ophthalmology \\
\hline 23 & $69 / 12$ & $\mathrm{~F}$ & orbital cellulitis & ethmoid, maxillary & proptosis, fever, eyelid edema & conservative therapy & ophthalmology \\
\hline 24 & $72 / 12$ & $\mathrm{~F}$ & orbital cellulitis & ethmoid, maxillary & $\begin{array}{c}\text { proptosis, headache, } \\
\text { eyelid edema }\end{array}$ & conservative therapy & pediatrics \\
\hline 25 & 3 & M & subperiosteal abscess & ethmoid, maxillary & $\begin{array}{l}\text { proptosis, headache, } \\
\text { eyelid edema }\end{array}$ & $\begin{array}{l}\text { ethmoidectomy, } \\
\text { intranasal antrostomy }\end{array}$ & ophthalmology \\
\hline 26 & $56 / 12$ & M & subperiosteal abscess & ethmoid & $\begin{array}{l}\text { proptosis, headache, } \\
\text { eyelid edema, fever }\end{array}$ & $\begin{array}{l}\text { ethmoidectomy, } \\
\text { abscess drainage }\end{array}$ & ophthalmology \\
\hline 27 & $210 / 12$ & $\mathrm{~F}$ & orbital cellulitis & ethmoid & $\begin{array}{l}\text { proptosis, fever, } \\
\text { nasal obstruction }\end{array}$ & conservative therapy & ENT \\
\hline 28 & $93 / 12$ & $\mathrm{~F}$ & orbital cellulitis & sphenoid, maxillary & proptosis, fever, eyelid edema & conservative therapy & pediatrics \\
\hline 29 & 6 & M & subperiosteal abscess & ethmoid, maxillary & $\begin{array}{c}\text { nausea, proptosis, } \\
\text { eyelid edema, fever }\end{array}$ & $\begin{array}{l}\text { ethmoidectomy, } \\
\text { abscess drainage }\end{array}$ & pediatrics \\
\hline 30 & 11 & M & orbital cellulitis & $\begin{array}{l}\text { ethmoid, sphenoid, } \\
\text { maxillary }\end{array}$ & $\begin{array}{l}\text { proptosis, fever, } \\
\text { nasal obstruction }\end{array}$ & conservative therapy & ophthalmology \\
\hline 31 & 5 & M & subperiosteal abscess & ethmoid, maxillary & proptosis, fever, eyelid edema & $\begin{array}{l}\text { ethmoidectomy, } \\
\text { intranasal antrostomy }\end{array}$ & ophthalmology \\
\hline
\end{tabular}


venous antibiotics in combination with glucocorticoid and oral gelomyrtol forte, and the patients were discharged from hospital on appropriate oral antibiotics for 4 weeks. All signs and symptoms of the 16 patients who received conservative therapy disappeared and there were no recurrences within the follow-up period of 1 to 8 years. The decreased vision of two patients (cases 6 and 8) with orbital cellulitis returned to normal on day 7 after sphenoidotomy or intranasal antrostomy. The nasal cavity of children is narrow, so nasal secretions cannot be cleaned timely and the incidence of nasal cavity adhesion will be obviously higher in pediatric patients than in the adult group after surgery. Accordingly, conservative therapy is more suitable for pediatric patients than surgical intervention. However, the symptoms and signs of orbital cellulitis should be closely observed and surgical intervention should be performed immediately if conservative therapy does not produce a rapid resolution of symptoms (13). We suggest that the surgical intervention should be performed as soon as possible for orbital SPA. SPA is an collection of pus which forms between the orbital periosteum and the bony wall of the orbit (Figure 2, 4). The abscess is usually between the lamina papyracea and the periorbita, occasionally on the superior orbital wall. Proptosis, chemosis and limited movement of the eyeball are common clinical manifestations (10). Orbital SPA is the most common indication for surgical drainage. Pond and Berkowitz (14) suggested that complete ethmoidectomy is not necessary for SPA since ethmoid disease can be cured by antibiotic therapy, but anterior ethmoidectomy is necessary to allow intranasal drainage of the SPA. In our opinion, complete opening of ethmoidal cellules is necessary for the drainage of the SPA in patients. Thus, the cases of sinusitis would be cured and the recurrence rate of SPA would be reduced. In our study, opening of ethmoidal cellules and abscess drainage were performed by ESS on 13 patients with SPA; the symptoms disappeared after 4 to 8 days.

Case 2 had two SPAs (Figure 4) located in the superiomedial orbit; sinusitis and the SPAs were cured at the same time. When part of the lamina papyracea was removed and orbital periosteum was detached from the superiomedial orbital wall, the abscess could be found in the roof of the orbit and purulent secretion was cleared off. In order to prevent serious orbital infection, orbital periosteum must be well protected. CT images should to be evaluated carefully before surgery and the best approach should be selected to reach the SPA.

It should be emphasized that initial symptoms of 10 patients were related to the eye, such as eyelid edema, proptosis and chemosis. Therefore, 25 of the patients were consulted initially by ophthalmologists or pediatricians. This could be the reason for a delay in diagnosis for some cases. Thus, close cooperation between ophthalmologists, pediatricians and otolaryngologists is very important for the correct diagnosis and treatment.

In conclusion, orbital complications secondary to acute rhinosinusitis are severe diseases. The initial symptoms are orbital rather than nasal in most pediatric patients. Therefore, close cooperation between ophthalmologists, pediatricians and otolaryngology doctors is very important for the correct diagnosis and treatment.

Conservative treatment is more suitable for inflammatory edema and orbital cellulitis in children than surgical intervention. However, surgical intervention should be applied to patients with orbital SPA as soon as possible.

Ethics Committee Approval: Ethics committee approval was received for this study from the ethics committee of Shandong Provincial Hospital Affiliated to Shandong University (Document number 2016062).

Informed Consent: Written informed consent was obtained from the parents of patients who participated in this study.

Peer-review: Externally peer-reviewed.

Author contributions: Concept - Y.Z.W., G.G.S., H.B.W.; Design - Y.Z.W., G.G.S., H.B.W.; Supervision - Y.Z.W., G.G.S., H.B.W.; Resource - Y.Z.W.; Materials - Y.Z.W., G.G.S., H.B.W.; Data Collection and/or Processing - Y.Z.W.; Analysis and/or Interpretation Y.Z.W., G.G.S., H.B.W.; Literature Search - Y.Z.W; Writing - Y.Z.W.; Critical Reviews - Y.Z.W., G.G.S., H.B.W.

Conflict of Interest: No conflict of interest was declared by the authors.

Financial Disclosure: This study was supported by the Natural Science Fund of China (NSFC30801279).

\section{REFERENCES}

1. Gallagher RM, Gross CW, Phillips CD. Suppurative intracranial complications of sinusitis. Laryngoscope 1998;108:1635-42. [Crossref]

2. Sow AJ, Jahendran J, Toh CJ, Kew TY. Sphenoethmoid sinusitis in a child resulting in a disastrous intracranial sequela. Ear Nose Throat J 2012;91:E20-2.

3. Ketenci İ, Ünlü Y, Vural A, Dogan H, Sahin MI, Tuncer E. Approaches to subperiosteal orbital abscesses. Eur Arch Otorhinolaryngol 2013;270:1317-27. [Crossref]

4. Eviatar E, Gavriel H, Pitaro K, Vaiman M, Goldman M, Kessler A. Conservative treatment in rhinosinusitis orbital complications in children aged 2 years and younger. Rhinology 2008;46:334-7. 
5. Rabuzzi DD, Hengerer AS. Complications of nasal and sinus infections. In: Bluestone CD, Stool SE, eds. Pediatric Otolaryngology. Philadelphia: WB Saunders Company 1990;p. 745-51.

6. Botting AM, McIntosh D, Mahadevan M. Pediatric pre- and post-septal peri-orbital infections are different diseases. A retrospective review of 262 cases. Int J Pediatr Otorhinolaryngol 2008;72:377-83. [Crossref]

7. Sultesz M, Csakanyi Z, Magoros T, Farkas Z, Katona G. Acute bacterial rhinosinusitis and its complications in our pediatric otolaryngolgical department between 1997 and 2006. Int J Pediatr Otorhinolaryngol 2009;73:1507-12. [Crossref]

8. Younis RT, Lazar RH, Anand VK. Intracranial complications of sinusitis: a 15-year review of 39 cases. Ear Nose Throat $J$ 2002;81:636-8, 640-2, 644.

9. Chandler JR, Langenbrunner DL, Stevens ER. The pathogenesis of orbital complications in acute sinusitis. Laryngoscope 1970; 80:1414-28. [Crossref]
10. Kayhan FT, Sayin I, Yazici ZM, Erdur O. Management of orbital subperiosteal abscess. J Craniofac Surg 2010;21:1114-7. [Crossref]

11. Oxford LE, McClay J. Complications of Acute Sinusitis in Children. Otolaryngol Head Neck Surg 2005;133:32-7. [Crossref]

12. Williams BJ, Harrison HC. Subperiosteal abscesses of the orbit due to sinusitis in childhood. Aust NZJ Ophthalmol 1991;19:2936. [Crossref]

13. Parvizi N, Choudhury N, Singh A. Complicated periorbital cellulitis: case report and literature review. J Laryngol Otol 2012;126:94-6. [Crossref]

14. Pond F, Berkowitz RG. Superolateral subperiosteal orbitalal bscess complicating sinusitis in a child. Int J Pediatr Otorhinolaryngol 1999;48:255-8. [Crossref] 